\title{
Increased Length of Stay of Critically Ill Patients in the Emergency Department Associated with Higher In-hospital Mortality
}

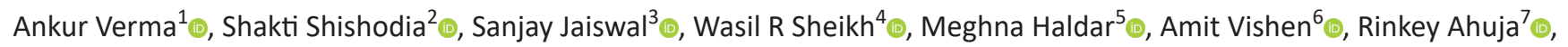
Abbas A Khatai ${ }^{8}$, Palak Khanna ${ }^{9}$

\begin{abstract}
Objectives: Emergency department (ED) length of stay (LOS) is defined as the time a patient is registered to the time the patient is shifted to a hospital bed or discharged. Increasing demand for quality emergency care has resulted in increased wait times due to demand and supply mismatch. It is perceived that longer LOS in the ED of critical patients leads to poor outcomes. Our goal was to study the impact of LOS in the ED on the patients who required critical care admissions.

Methods: This was a retrospective study conducted in the ED of a tertiary center. Data were collected using electronic health records (EHR) for patients admitted to the intensive care units (ICUs). Patient's LOS in ED was divided into $0-4,4-8,8-12,12-24$, and $>24$ hours. ED LOS was calculated from the registration time to the time patient was handed over in the ICU. Patients were divided into four categories (1-4) based on their criticality. LOS in ED, mortality, and total hospital LOS were analyzed in the study.

Results: Three thousand four hundred and twenty-nine patients were enrolled in the study. Mean age was 62.69 years (95\% Cl 62.11-63.26). A total of $42.09 \%$ (95\% Cl 40.5-43.8) were Category 1 patients. Overall mortality rate was $52.46 \%$ (95\% Cl 50.79-54.13). LOS of $48.15 \%$ (95\% $\mathrm{Cl} 46.54-49.88)$ patients in the ED was between 0 and 4 hours, $19.90 \%(95 \% \mathrm{Cl} 18.62-21.29)$ between 4 and 8 hours, $8.21 \%(95 \% \mathrm{Cl} 7.35-9.19)$ between 8 and 12 hours, $15.50 \%(95 \% \mathrm{Cl} 14.34-16.77)$ between 12 and 24 hours, and $8.13 \%(95 \% \mathrm{Cl} 7.27-9.10)>24$ hours. Mortality for LOS of 0-4 hours was 51.30\% (95\% Cl 48.89-53.70), 54.03\% (95\% Cl 50.28-57.73) for 4-8 hours, $48.94 \%$ (95\% Cl 43.16-54.75) for 8-12 hours, 51.50\% (95\% Cl 47.26-55.72) for $12-24$ hours, and $60.57 \%$ ( $95 \%$ Cl $54.73-66.13$ ) for $>24$ hours.

Conclusion: We concluded that the longer the critically ill patients are boarded in the ED, the higher is the chance for mortality. Processes should be implemented to ease the throughput from the ED.

Keywords: Emergency overcrowding, Mortality, Throughput.

Indian Journal of Critical Care Medicine (2021): 10.5005/jp-journals-10071-24018
\end{abstract}

\section{HIGHLIGHTS}

Impact of ED LOS of critical patients on their outcomes has not been studied previously in India. Our study aimed at providing insight into their outcomes and guided our department and hospital to adjust processes and protocols according to the results attained.

\section{INTRODUCTION}

The emergency department (ED) is the safety net for the community visited by one and all irrespective of the hospital (public v/s private) setting, disease acuity, socioeconomic status, gender, age, etc. ED overcrowding can be called a pandemic. Overcrowding in the EDs is now a public health problem that has become one of the most important issues faced by hospitals across the world. Studies have identified many factors for ED overcrowding. These include nonurgent visits, demand and supply mismatch, shortage of trained and appropriate staff, insufficient inpatient beds among others. ${ }^{1-3}$ ED crowding can lead to increased length of stay (LOS), long wait times for patients to be seen, and high rates of patient dissatisfaction. Many adverse events like increased in-patient mortality, medication delays and errors, and unrecognized complications have occurred due to overcrowding. ${ }^{4-8}$ Absconding patients and financial loss to the provider have also been reported as consequences of ED overcrowding. ${ }^{9,10}$ Many strategies to counter
${ }^{1-9}$ Department of Emergency Medicine, Max Super Speciality Hospital, Delhi, India

Corresponding Author: Ankur Verma, Department of Emergency Medicine, Max Super Speciality Hospital, Delhi, India, Phone: +91 9971779998, e-mail: anksv25@gmail.com

How to cite this article: Verma A, Shishodia S, Jaiswal S, Sheikh WR, Haldar M, Vishen A, et al. Increased Length of Stay of Critically III Patients in the Emergency Department Associated with Higher Inhospital Mortality. Indian J Crit Care Med 2021;25(11):1221-1225.

Source of support: Nil

Conflict of interest: None

the problem have been proposed, but with the ever-growing population, increasing recognition of emergency medicine, need for quality acute and emergency care, this pandemic of ED crowding is far from getting under control. ${ }^{11}$

Emergency medicine is still in its nascent stages in India. Many urban tertiary care healthcare providers have recognized the need for large academic emergency medicine departments manned by trained physicians and nurses. But with a population of 136.64 crores, the second largest in the world, even the best and largest of EDs get overwhelmed with high volume of patients. Saqib and Qazi in their paper noted that the reason 
for increased LOS in a pediatric ED in India was unavailability of beds, incubator and ventilators, laboratory delays, and patients coming for intravenous or intramuscular injections. ${ }^{12}$ There have been no other substantial studies conducted regarding ED overcrowding and its effects on patient outcomes in our country. The aim of our study was to evaluate the impact of LOS in the ED with patient outcomes vis-a-vis in-hospital mortality and total LOS in the hospital.

\section{Materials and Methods}

\section{Study Design and Setting}

This was a retrospective cohort study to evaluate the impact of LOS in the ED on the outcome of patients who required critical care admission. Our study was approved by the Institutional Ethics Committee and was exempted from informed consent. Data were collected from the electronic health records (EHR) of the patients who had presented to our 30-bedded urban ED of a 400-bedded tertiary care center in New Delhi, India, between March 2017 and November 2019. Hospital Information System (HIS) was accessed to extract the list of the patients who had been admitted to the intensive care units (ICUs) from our ED during the study period. Patient data were then collected from the EHR. LOS in the ED was defined as the time between the registration of the patient in the ED and the time when the patient was handed over to the ICU which is documented in the EHR by the receiving doctors and nurses. The clinical conditions of the patients were divided into four categories as per the Canadian Triage and Acuity Scale. ${ }^{13}$ Category 1 (Resuscitation) was comprised of critical patients requiring hourly and/or invasive monitoring. Category 2 (Emergent) was comprised of unstable patients who needed nursing interventions, laboratory workup, and/or monitoring every 2-4 hours. In Category 3 (Urgent), stable patients who needed close monitoring or laboratory work every 2-4 hours were included. Category 4 (Semiurgent) was comprised of stable patients who needed testing and monitoring not more frequently than every 4 hours. All adults above 18 years of age who were admitted to the ICU during the study period were included in the study. Patients who left against medical advice or were transferred from another hospital after receiving primary care were excluded from the study. LOS and outcome were collected and analyzed in each clinical category of patients. LOS was divided into $0-4,4-8$, $8-12,12-24$, and $>24$ hours. The primary outcome of our study was in-hospital mortality. Secondary outcome was the total LOS. The total LOS was calculated from the time of admission to the time of discharge extracted from the HIS.

\section{Statistical Analysis}

Descriptive statistics were used to evaluate the association between length of ED boarding and hospital LOS, subsequent transfer to an ICU, and mortality. Descriptive statistics were also used to calculate the association between ED crowding, LOS, and mortality. Continuous data presented as means and 95\% confidence interval were compared with the analysis of variance (ANOVA). Regression analysis was performed to identify the factors associated with the outcomes of the patients and admission to the ICU while a simple linear regression technique was performed to identify factors directly associated with patients' LOS. Standard error was calculated and examined to understand fitting among the predictors. The data analysis was carried out using software IBM SPSS, MS-Excel, and R Programming.

\section{Results}

A total of 3,429 patients were recruited for the study who were admitted into the ICUs during the study period. Mean age of the patients was 62.69 years $(95 \% \mathrm{Cl} 62.11-63.26)$. A total of $64.15 \%$ (95\% 62.54-65.75) patients admitted were males. Table 1 lists all the demographic and clinical characteristics of the study subjects.

Total mortality rate was $52.46 \%(95 \% \mathrm{Cl} 50.79-54.13)$. Out of the total number of patients enrolled, $42.09 \%$ (95\% Cl 40.5-43.8) were Category 1 patients. Table 2 summarizes the categories of the patients enrolled in the study. Out of all the mortalities, $64.48 \%$ were in the geriatric population ( $\geq 60$ years).

The LOS of $48.15 \%(95 \% \mathrm{Cl} 46.54-49.88)$ patients in the ED was between 0 and 4 hours. Table 3 summarizes the LOS of patients in the ED.

Table 1: Demographic and clinical characteristics of study subjects

\begin{tabular}{lcc}
\hline Characteristics & \multicolumn{2}{c}{$n=3,429$} \\
\hline Mean age \pm SD & \multicolumn{2}{c}{$62.69 \pm 17.05$} \\
Male (\%) & 2,200 & 64.16 \\
Specialty admissions & $n$ & $\%$ \\
Cardiology & 1,155 & 33.68 \\
CTVS & 57 & 1.66 \\
ENT & 1 & 0.03 \\
Gastro & 269 & 7.84 \\
General surgery & 136 & 3.97 \\
Hematology & 46 & 1.34 \\
Internal medicine & 215 & 6.27 \\
Nephrology & 183 & 5.34 \\
Neurology & 440 & 12.83 \\
Neurosurgery & 212 & 6.18 \\
Oncosurgery & 11 & 0.32 \\
Oncology & 339 & 9.89 \\
Pulmonology & 336 & 9.80 \\
Urology & 20 & 0.58 \\
Vascular surgery & 9 & 0.26 \\
\hline n number of &
\end{tabular}

$n$, number of patients; \%, percentage of patients

Table 2: Categories of patients in study population

\begin{tabular}{lcl}
\hline Category & $n$ & $\%(95 \% \mathrm{Cl})$ \\
\hline 1 & 1,445 & $42.09(40.5-43.8)$ \\
2 & 937 & $27.29(25.86-28.84)$ \\
3 & 638 & $18.58(17.34-19.94)$ \\
4 & 409 & $11.91(10.89-13.06)$ \\
\hline
\end{tabular}

$n$, number of patients; $\%$, percentage of patients

Table 3: Distribution of patients according to LOS in ED

\begin{tabular}{lcc}
\hline LOS in $E D$ & $n$ & $\%(95 \% \mathrm{Cl})$ \\
\hline $0-4$ hours & 1,653 & $48.15(46.54-49.88)$ \\
$4-8$ hours & 683 & $19.90(18.62-21.29)$ \\
$8-12$ hours & 282 & $8.21(7.35-9.19)$ \\
$12-24$ hours & 532 & $15.50(14.34-16.77)$ \\
$>24$ hours & 279 & $8.13(7.27-9.10)$ \\
\hline
\end{tabular}

$n$, number of patients; $\%$, percentage of patients 
Table 4: Category (severity)-wise distribution of LOS

\begin{tabular}{|c|c|c|c|c|c|c|c|c|}
\hline \multirow{3}{*}{$\begin{array}{l}\angle O S \\
\text { in } E D\end{array}$} & \multicolumn{8}{|c|}{ Categories } \\
\hline & \multicolumn{2}{|r|}{$\begin{array}{c}1 \\
(n=1,445)\end{array}$} & \multicolumn{2}{|r|}{$\begin{array}{c}2 \\
(n=937)\end{array}$} & \multicolumn{2}{|r|}{$\begin{array}{c}3 \\
(n=638)\end{array}$} & \multicolumn{2}{|r|}{$\begin{array}{c}4 \\
(n=409)\end{array}$} \\
\hline & $n$ & $\%(95 \% \mathrm{Cl})$ & $n$ & $\%(95 \% \mathrm{Cl})$ & $n$ & $\%(95 \%$ Cl) & $n$ & $\%(95 \% \mathrm{Cl})$ \\
\hline $\begin{array}{l}0-4 \\
\text { hours }\end{array}$ & 717 & $49.62(47.05,52.19)$ & 429 & $45.78(42.62,48.99)$ & 308 & $48.28(44.42,52.15)$ & 199 & $48.66(43.85,53.49)$ \\
\hline $\begin{array}{l}4-8 \\
\text { hours }\end{array}$ & 295 & $20.42(18.42,22.57)$ & 186 & $19.85(17.42,22.53)$ & 123 & $19.28(16.41,22.52)$ & 79 & $19.32(15.78,23.42)$ \\
\hline $\begin{array}{l}8-12 \\
\text { hours }\end{array}$ & 98 & $6.78(5.60,8.20)$ & 97 & $10.35(8.56,12.47)$ & 58 & $9.09(7.10,11.57)$ & 29 & $7.09(4.98,10.00)$ \\
\hline $\begin{array}{l}12-24 \\
\text { hours }\end{array}$ & 219 & $15.16(13.40,17.10)$ & 141 & $15.05(12.9,17.48)$ & 104 & $16.30(13.64,19.37)$ & 68 & $16.63(13.33,20.54)$ \\
\hline $\begin{array}{l}>24 \\
\text { hours }\end{array}$ & 116 & $8.03(6.74,9.54)$ & 84 & $8.96(7.30,10.97)$ & 45 & $7.05(5.31,9.31)$ & 34 & $8.31(6.01,11.39)$ \\
\hline
\end{tabular}

Table 5: Mortality among the different types of LOS

\begin{tabular}{|c|c|c|c|c|}
\hline \multirow[b]{3}{*}{$\angle O S$ in ED } & \multicolumn{4}{|c|}{ Mortality } \\
\hline & \multicolumn{2}{|c|}{ No } & \multicolumn{2}{|c|}{ Yes } \\
\hline & $n$ & $\%$ & $n$ & $\%$ \\
\hline $0-4$ hours & 805 & 48.70 & 848 & 51.30 \\
\hline $4-8$ hours & 314 & 45.97 & 369 & 54.03 \\
\hline $8-12$ hours & 144 & 51.06 & 138 & 48.94 \\
\hline $12-24$ hours & 258 & 48.50 & 274 & 51.50 \\
\hline$>24$ hours & 110 & 39.43 & 169 & 60.57 \\
\hline
\end{tabular}

$n$, number of patients; $\%$, percentage of patients

Table 6: Mortality as per categories of patients

\begin{tabular}{lccccc}
\hline & \multicolumn{4}{c}{ Mortality } \\
\cline { 2 - 3 } \cline { 5 - 5 } \cline { 5 - 5 } Category & \multicolumn{3}{c}{ No } & & \multicolumn{2}{c}{ Yes } \\
\cline { 2 - 3 } \cline { 5 - 6 } & 596 & 41.25 & & 849 & 58.75 \\
2 & 370 & 39.49 & & 567 & 60.51 \\
3 & 355 & 55.64 & & 283 & 44.36 \\
4 & 310 & 75.79 & & 99 & 24.21 \\
\hline
\end{tabular}

$n$, number of patients; $\%$, percentage of patients

Out of all the Category 1 patients, $49.62 \%(95 \% \mathrm{Cl} 47.05-$ 52.19), 20.42\% (95\% Cl 18.42-22.57), 6.78\% (95\% Cl 5.60-8.20), $15.16 \%$ (95\% Cl 13.40-17.10), and $8.03 \%$ (95\% Cl 6.74-9.54) patients had an ED LOS of $0-4,4-8,8-12,12-24$, and $>24$ hours, respectively. Table 4 summarizes category-wise distribution of the LOS of patients enrolled in the study.

As shown in Table 5, the overall mortality for patients staying in the ED was $51.30 \%(95 \% \mathrm{Cl} 48.89-53.70)$ for $0-4$ hours, $54.03 \%$ (95\% Cl 50.28-57.73) for 4-8 hours, $48.94 \%$ (95\% Cl 43.16-54.75) for $8-12$ hours, $51.50 \%(95 \% \mathrm{Cl} 47.26-55.72)$ for $12-24$ hours, and $60.57 \%$ (95\% Cl 54.73-66.13) for $>24$ hours.

Out of all the Category 1 patients, the mortality was $58.75 \%$ (95\% Cl 56.20-61.27), in Category 2 patients $60.51 \%(95 \% \mathrm{Cl}$ 57.35-63.59), in Category 3 patients $44.36 \%(95 \% \mathrm{Cl} 40.55-48.33)$, and in Category 4 patients $24.21 \%(95 \% \mathrm{Cl} 20.31-28.58)$ as shown in Table 6.
Table 7: Total LOS of critical patients presenting to the ED

\begin{tabular}{lcc}
\hline Total LOS & & \\
\hline Mean \pm SD & & $6.82 \pm 9.64$ \\
Median & 3.00 \\
Range & & $0-150$ \\
\hline Total LOS & $n$ & $\%$ \\
\hline $0-15$ & 3,006 & 87.55 \\
$15-30$ & 307 & 8.95 \\
$30-45$ & 80 & 2.33 \\
$45-60$ & 18 & 0.52 \\
$60-75$ & 12 & 0.35 \\
$75-90$ & 2 & 0.06 \\
$90-105$ & 2 & 0.06 \\
$105-120$ & 1 & 0.03 \\
$120-135$ & - & - \\
$135-150$ & 1 & 0.03 \\
\hline$n$, number of patients; \%, percentage of patients
\end{tabular}

Category 1 patients who had an ED LOS of 0-4 hours had a mortality of $57.46 \%$ (95\% Cl 53.81-61.03), $4-8$ hours had $63.05 \%$ (95\% Cl 57.41-68.36), 8-12 hours had 56.12\% (95\% Cl 46.25-65.53), $12-24$ hours had $55.71 \%(95 \% \mathrm{Cl} 49.09-62.13)$, and $>24$ hours had $63.79 \%$ (95\% Cl 54.74-71.97). In-hospital mortality in Category 2 patients who had an ED LOS of 0-4 hours was $60.14 \%(95 \% \mathrm{Cl}$ $55.44-64.66)$ and $>24$ hours was $69.05 \%$ (95\% Cl 58.51-77.92). 


\begin{tabular}{|c|c|}
\hline Cause of death $(n=1,799)$ & $\%(n)$ \\
\hline Severe sepsis and septic shock & $45.02(810)$ \\
\hline Other trauma & $2.27(41)$ \\
\hline Traumatic brain injury & $2.11(38)$ \\
\hline Acute kidney injury & $7.55(136)$ \\
\hline Acute ischemic stroke & $3.001(54)$ \\
\hline Acute hemorrhagic stroke & $5.16(93)$ \\
\hline Polytrauma & $1.55(28)$ \\
\hline Myocardial infarction & $8.22(148)$ \\
\hline Cardiogenic shock & $2.72(49)$ \\
\hline Dengue shock syndrome & $2.22(40)$ \\
\hline Aortic stenosis & $0.22(4)$ \\
\hline Mitral stenosis & $0.11(2)$ \\
\hline Dyselectrolytemia & $0.88(16)$ \\
\hline Upper gastrointestinal bleed & $0.88(16)$ \\
\hline Aortic dissection & $0.61(11)$ \\
\hline Malignancy & $6.22(112)$ \\
\hline Complete heart block & $0.16(3)$ \\
\hline Guillain-Barre syndrome & $0.05(1)$ \\
\hline Hepatic failure & $0.27(5)$ \\
\hline Aspiration pneumonia & $1.11(20)$ \\
\hline Rupture ectopic pregnancy & $0.05(1)$ \\
\hline Fat embolus & $0.05(1)$ \\
\hline Hanging & $0.05(1)$ \\
\hline Meningoencephalitis & $0.67(12)$ \\
\hline Heart failure & $3.11(56)$ \\
\hline Pneumothorax & $0.16(3)$ \\
\hline Cardiac tamponade & $0.11(2)$ \\
\hline Pulmonary embolism & $0.55(10)$ \\
\hline Pulmonary edema & $0.61(11)$ \\
\hline Pancreatitis & $0.16(3)$ \\
\hline Stuck valve & $0.05(1)$ \\
\hline Peritonitis & $0.05(1)$ \\
\hline Perforation & $0.27(5)$ \\
\hline Status epilepticus & $0.05(1)$ \\
\hline Interstitial lung disease & $0.05(1)$ \\
\hline Acute respiratory distress syndrome & $1.39(25)$ \\
\hline Dyselectrolytemia & $0.89(16)$ \\
\hline Poisoning & $1.22(22)$ \\
\hline
\end{tabular}

$n$, number of patients; $\%$, percentage of patients

In Category 3 patients, in-hospital mortality increased from $42.86 \%(95 \% \mathrm{Cl} 37.45-48.44)$ in patients who stayed from $0-4$ hours to $60 \%(95 \% \mathrm{Cl} 45.45-72.98)$ in patients who stayed $>24$ hours. For Category 4 patients, the mortality increased from $23.12 \%(95 \% \mathrm{Cl} 17.80-29.45)$ to $29.41 \%$ (95\% Cl 16.83-46.17) for ED LOS $>24$ hours. Figure 1 depicts the mortalities against the LOS as per the category of patients. About $87.55 \%$ of the patients had a total LOS of 0-15 days. Table 7 summarizes the total LOS of the patients.

Severe sepsis and septic shock were the most common causes of mortality (45.02\%). Table 8 enlists the causes of mortality in the included patients.

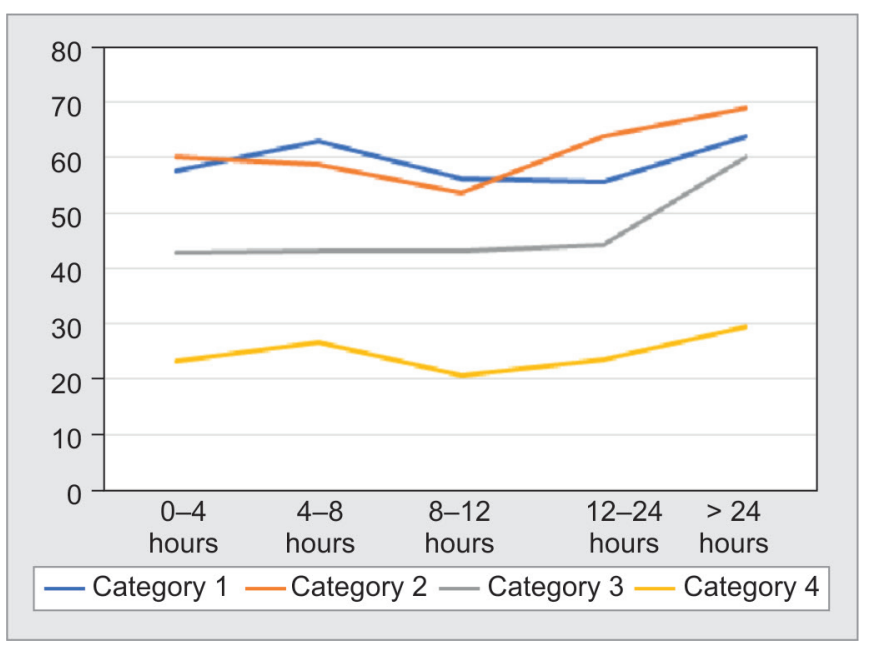

Fig. 1: Mortality associated with the LOS for each category of patients

\section{Discussion}

In our study, it was found that the longer a patient is boarded in the ED, the more is the risk for mortality. This was true for all the severity categories of the patients. Mortality rates for patients staying in the ED for more than 24 hours were the highest among all the LOS brackets for each category. In the year 2004, the National Health Service (NHS) introduced the "4-hour rule." They strategized and advocated that $>90 \%$ of the patients visiting the ED should be seen, evaluated, investigated, diagnosed, and disposed (admitted/discharged) within 4 hours of arrival to the ED. ${ }^{14}$ Most of the patients requiring critical care admissions who presented to our department had a LOS of up to 4 hours. Saukkonen et al. performed a prospective follow-up cohort in a university hospital which concluded that there was no corelation between the LOS in the ED and the hospital mortality. It was also stated in their study that the higher LOS, advanced age, and lower educational background had a statistically significant negative impact on the measures of quality of life. ${ }^{15}$ However, in our study we found that in-hospital mortality was associated with increased LOS in the ED. Liu et al. performed a retrospective chart abstraction to track the frequency of undesirable events and found that there was a substantial increase in the frequency of undesirable events, such as missed medications, missed laboratory test results, arrhythmias, or other adverse events, while patients board in the ED. Older patients or those with more comorbidities seemed to have fared worse as compared to the rest of the study population. ${ }^{16}$ Our study had a similar finding with almost $65 \%$ of the mortalities occurring in patients $\geq 60$ years of age. One of the reasons for patients' increased LOS in the ED is due to nonavailability of appropriate ICU beds. This in turn hampers the throughput of these critically ill patients and contributes to ED overcrowding. An overcrowded ED full of critically ill patients may delay delivery of quality clinical care (due to limited resources) to such patients and to other patients that are presenting to the ED concurrently. This becomes a vicious cycle and until patients are not admitted to the required beds, the ED remains overcrowded. Timely transfer to the ICU is one of the factors in reducing crowding. ${ }^{17}$ The cause of ED overcrowding includes many complex processes and have multiple stakeholders. This includes in-patient bed availability, time for diagnostics, footfalls, skilled 
manpower, and resources. This crowding can lead to prolonged LOS of patients and undesirable outcomes for patients.

A major limitation of our study was that we did not take into account the critical patients who might have had a long stay in the ED and expired in the ED itself. This would have led to an underestimation of the burden. Being a retrospective study, it may have been prone to a selection bias.

\section{Conclusion}

Our study concluded that prolonged LOS of critically ill patients in the ED in our hospital is associated with increased in-hospital mortality. The mortality rate increases even further in patients who are boarded in the emergency for more than 24 hours and those who are elderly. Systems, processes, resources, and skills should be worked upon with all the stakeholders to improve throughput and reduce crowding and prolonged LOS in the ED.

\section{Disclaimer}

The views expressed in the submitted article are the authors' own and not an official position of the institution. The authors have not received any funding for the said study.

\section{Author Contributions}

Shishodia S was the primary investigator. Shishodia S and Verma A designed the study and were the lead in manuscript preparation and data analysis. All other coauthors contributed toward literature review and critical feedback and helped shape the research, analysis, and manuscript. Khanna provided the statistical analysis for the study.

\section{Ethical Approval}

The study was approved by the Institutional Review Board.

\section{OrCID}

Ankur Verma $\odot$ https://orcid.org/0000-0001-9524-9164 Shakti Shishodia • https://orcid.org/0000-0001-7148-0484 Sanjay Jaiswal 이 https://orcid.org/0000-0001-5333-8230 Wasil R Sheikh (1) https://orcid.org/0000-0001-8479-7632

Meghna Haldar $\odot$ https://orcid.org/0000-0001-8639-0510

Amit Vishen () https://orcid.org/0000-0001-5705-266X

Rinkey Ahuja @ https://orcid.org/0000-0002-3009-5173

Abbas A Khatai @ https://orcid.org/0000-0001-8697-0742

Palak Khanna (1) https://orcid.org/0000-0002-0360-7006

\section{References}

1. Hoot NR, Aronsky D. Systematic review of emergency department crowding: causes, effects, and solutions. Ann Emerg Med 2008;52(2):126-136. DOI: 10.1016/j.annemergmed.2008.03.014.

2. Asplin BR, Magid DJ, Rhodes KV, Solberg LI, Lurie N, Camargo CA J. A conceptual model of emergency department crowding. Ann Emerg Med 2003;42(2):173-180. DOI: 10.1067/mem.2003.302.
3. Schneider SM, Gallery ME, Schafermeyer R, et al. Emergency department crowding: a point in time. Ann Emerg Med 2003 8;42(2):167-72. DOI: 10.1067/mem.2003.258. PMID: 12883503.

4. Miro O, Antonio MT, Jimenez S, De Dios A, Sánchez M, Borrás A, et al. Decreased health care quality associated with emergency department overcrowding. Eur J Emerg Med 1999;6(2):105-107. DOI: 10.1097/00063110-199906000-00003. PMID: 10461551.

5. Richardson DB. Increase in patient mortality at 10 days associated with emergency departmentovercrowding.Med J Aust 2006;184(5):213-216. DOI: 10.5694/j.1326-5377.2006.tb00204.x. PMID: 16515430.

6. Liu S, Hobgood C, Brice JH. Impact of critical bed status on emergency department patient flow and overcrowding. Acad Emerg Med 2003;10(4):382-385. DOI: 10.1111/j.1553-2712.2003.tb01353.x. PMID: 12670854.

7. Schull MJ, Vermeulen M, Slaughter G, Morrison L, Daly P. Emergency department crowding and thrombolysis delays in acute myocardial infarction. Ann Emerg Med 2004;44(6):577-585. DOI: 10.1016/j. annemergmed.2004.05.004. PMID: 15573032.

8. Liu SW, Chang Y, Weissman JS, Griffey RT, Thomas J, Nergui S, et al. An empirical assessment of boarding and quality of care: delays in care among chest pain, pneumonia, and cellulitis patients. Acad Emerg Med 2011;18(12):1339-1348. DOI: 10.1111/j.1553-2712.2011.01082.x.

9. Baker DW, Stevens CD, Brook RH. Patients who leave a public hospital emergency department without being seen by a physician. Causes and consequences. JAMA 1991;266(8):1085-1090. DOI: 10.1001/ jama.1991.03470080055029. PMID: 1865540.

10. Bayley MD, Schwartz JS, Shofer FS, Weiner M, Sites FD, Traber KB, et al. The financial burden of emergency department congestion and hospital crowding for chest pain patients awaiting admission. Ann Emerg Med 2005;45(2):110-117. DOI: 10.1016/j. annemergmed.2004.09.010. PMID: 15671965.

11. ACEP. Task force report on boarding emergency department crowding high-impact solutions. Irving: American College of Emergency Physicians; 2008.

12. Saqib N, Qazi M. Factors associated with overcrowded pediatric emergency rooms in Northern India and possible solutions: a medical school setting. Int J Contemp Pediatr 2019;6(3):911-916. DOI: 10.18203/2349-3291.ijcp20191993.

13. Rose L, Scales DC, Atzema C, Burns KE, Gray S, Doing C, et al. Emergency department length of stay for critical care admissions. A population-based study. Ann Am Thorac Soc 2016;13(8):1324-1332. DOI: 10.1513/AnnalsATS.201511-7730C. PMID: 27111127.

14. Department of Health. Transforming emergency care in England. 2004.

15. Saukkonen KA, Varpula M, Räsänen P, Roine RP, Voipio-Pulkki LM, Pettilä V. The effect of emergency department delay on outcome in critically ill medical patients: evaluation using hospital mortality and quality of life at 6 months. J Intern Med 2006;260(6):586-591. DOI: 10.1111/j.1365-2796.2006.01716.x. PMID: 17116010.

16. Liu SW, Thomas SH, Gordon JA, Hamedani AG, Weissman JS. A pilot study examining undesirable events among ED -boarded patients awaiting inpatient beds. Ann Emerg Med 2009;54(3):381-385. DOI: 10.1016/j.annemergmed.2009.02.001. PMID: 19303168.

17. Cline SD, Schertz RA, Feucht EC. Expedited admission of patients decreases duration of mechanical ventilation and shortens ICU stay. Am J Emerg Med 2009;27(7):843-846. DOI: 10.1016/j. ajem.2008.04.018. PMID: 19683114. 